CEOMETRICAL FOUNDATIONS OF

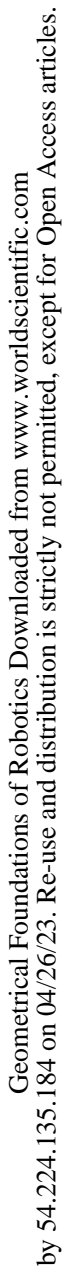

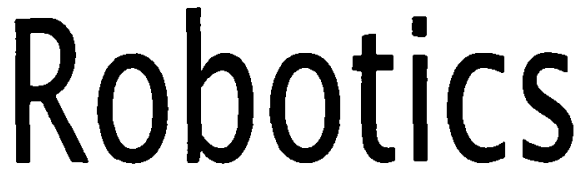


This page is intentionally left blank 


\section{GEOMETRICAL FOUNDATIONS OF}

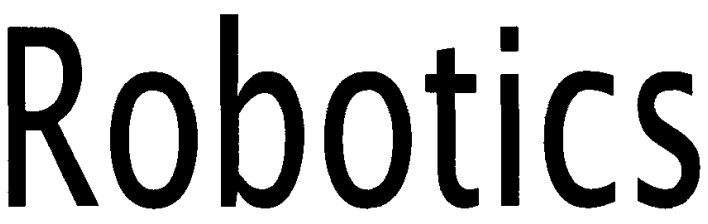

\section{EDITOR}

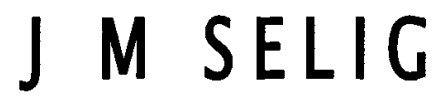

School of Computing

Information Systems and Mathematics

South Bank University

UK 


\section{Published by}

World Scientific Publishing Co. Pte. Led.

P O Box 128, Farrer Road, Singapore 912805

USA office: Suite IB, 1060 Main Street, River Edge, NJ 07661

$U K$ office: 57 Shelton Street, Covent Garden, London WC2H 9HE

\section{British Library Cataloguing-in-Publication Data}

A catalogue record for this book is available from the British Library.

\section{GEOMETRICAL FOUNDATIONS OF ROBOTICS}

Copyright $\odot 2000$ by World Scientific Publishing Co. Pte. Ltd.

All rights reserved. This book, or parts thereof, may not be reproduced in any form or by any means, electronic or mechanical, including photocopying, recording or any information storage and retrieval system now known or to be invented, without written permission from the Publisher.

For photocopying of material in this volume, please pay a copying fee through the Copyright Clearance Center, Inc., 222 Rosewood Drive, Danvers, MA 01923, USA. In this case permission to photocopy is not required from the publisher.

ISBN $981-02-4113-5$

This book is printed on acid-free paper.

Printed in Singapore by Uto-Print 


\section{Preface}

These notes were delivered at a one day tutorial session at the 1998 IEEE International conference on robotics and automation, Leuven, Belgium.

Like the tutorial the note are intended to introduce some of the basic ideas of modern differential geometry and give concrete examples of applications to robotics.

Robotics is an intensely practical discipline, it is always fair to ask about the implication of a theoretical idea. In the past the case for the modern geometry we discuss here, has not always be clear to everyone. Some argued that the geometrical viewpoint was nothing more than a 'fancy notation'. Even if this were the case, it would not be a fatal criticism, since a good notation is almost always a key to progress. But geometry is much more than a good notation. The modern literature on the subject is huge and a surprising amount has fairly direct applications in robotics.

At present, the subject of geometrical applications in robotics has reached a state of maturity where its achievements are obvious. The promise for future success is undoubted, many areas of robotics will benefit from the contributions of geometers.

The material selected for these notes is deliberately hetrogeneous. The first three chapters are introductory in nature and are intended to outline the ideas of Lie groups and Lie algebras. These concepts form one of the main foundations of modern differential geometry and are key in understanding many ideas in robotics. The material is supported and illustrated with straightforward applications to robotics. In particular, the standard example of a Lie group will be the group of rigid body transformations. This example is very familiar in robotics as a set of transformation matrices. 
The remaining five chapters are intended to give a taste of some of the more advanced problems that can be understood with the aid of modern geometry. Applications such as the design of robot mechanisms, the analysis of robot singularities and computability of geometric calculus will be considered. These areas are at the leading edge of robotics and mathematics research. The talks present an overview of these subjects and are written by some of the leading researchers in the field.

The aim of the tutorial and of these notes is to encourage workers, both in robotics and mathematics to learn, use and extend these ideas. Ultimately we hope to show that the foundations of robotics are geometrical. More precisely, it is the geometry of 3-dimensional Euclidean space which underpin the discipline of robotics. This view does not diminish the problems of robotics, since a study of robotics uncovers many difficult and, as yet, unsolved problems in Euclidean geometry.

\section{Further Reading}

In these short notes we cannot hope to cover the whole subject. The following books should be consulted for a more comprehensive account of the applications of geometry to robotics.

[1] A. Karger and J. Novak. Space Kinematics and Lie Groups. Gordon and Breach, New York, 1985.

[2] R.W. Murray Z. Li and S.S. Sastry. A Mathematical Introduction to Robot Manipulation. CRC Press, Boca Raton, 1993.

[3] J.M. Selig. Geometrical Methods in Robotics. Springer Verlag, New York, 1996.

For more detail on the geometry itself, the following short list details some of the more accessible texts in this area.

[1] M. Berger and B. Gostiaux. Differential geometry: Manifolds, Curves and Surfaces. Springer Verlag, New York, 1988.

[2] W.L. Burke. Applied Differential Geometry. Cambridge University Press, Cambridge, 1985.

[3] R. Gilmore. Lie Groups, Lie Algebras, and some of their Applications. John Wiley and Sons, New York, 1974. 
[4] B. F.Schutz. Geometrical Methods of Mathematical Physics. Cambridge University Press, Cambridge, 1980.

\section{Acknowledgement}

It is with genuine pleasure that I thank the IEEE Robotics and automation society for giving us the opportunity to present this material in Leuven. In particular I would like to thank Ken Goldberg, the tutorials and workshop organiser, for his help and encouragement.

J.M. Selig, London 1999 
This page is intentionally left blank 


\section{Contents}

Preface v v

Lecture 1 Groups by J.M. Selig 1

1.1 Definition of a Group . . . . . . . . . . . . . . 1

1.2 Rotations and Translations . . . . . . . . . . 6

1.3 The Group of Rigid Body Transformations . . . . . . . . 9

Lecture 2 Subgroups and Representations by J.M. Selig 15

2.1 Subgroups of $S E(3) \ldots \ldots \ldots \ldots \ldots \ldots$

2.2 Mechanical Joints and Grasping ............. 17

2.3 Homomorphisms . . . . . . . . . . . . . . 21

2.4 Representations ...................... 22

Lecture 3 Lie Algebras by J.M. Selig 27

3.1 Derivatives . . . . . . . . . . . . . . . . . . 27

3.2 Robot Kinematics . . . . . . . . . . . . . 30

3.3 Algebraic Properties .................. 32

3.4 The Exponential Mapping . . . . . . . . . . . . . 35

Lecture 4 Design of New Mechanisms via the Displacement Subgroups by J.M. Hervé $\quad 39$

4.1 Introduction . . . . . . . . . . . . . . . . . . 39

4.2 Geometrical Preliminaries . . . . . . . . . . . . . . . 40

4.3 The Velocity Field for a Rigid Body Motion . . . . . . . . . 41

4.4 The Lie Algebra of Screws . . . . . . . . . . . . . . . . . 43

4.5 The Displacement Subgroups . . . . . . . . . . . . . 48 
4.6 Mechanical Bonds . . . . . . . . . . . . . . . . . . . 49

4.7 Application: Translating In-Parallel Actuated Platforms . . . . 56

Lecture 5 Kinematics from the Singular Viewpoint by $\begin{array}{ll}\text { C.G. Gibson } & 61\end{array}$

5.1 Background . . . . . . . . . . . . . . . 61

5.2 Spaces of Interesting Objects . . . . . . . . . . . 62

5.3 Families of Interesting Objects . . . . . . . . . . . . 64

5.4 Transversality Theorems . . . . . . . . . . . . 65

5.5 Planar Motions with 1-degree-of-freedom $\ldots \ldots \ldots 67$

5.6 Planar Motions with 2-degrees-of-freedom . . . . . . . . 73

5.7 The Outlook . . . . . . . . . . . . . . . . 78

Lecture 6 Singularity Analysis of Serial Robot-Manipulators $\begin{array}{ll}\text { by } A \text {. Karger } & 81\end{array}$

6.1 Introduction. . . . . . . . . . . . . . . . . 81

6.2 Notations and Basic Properties . . . . . . . . . . . . . 82

6.3 Singular Sets of RMs with $p \neq 6$ degrees-of-freedom $\ldots \ldots .83$

6.4 Singularity Analysis of 6-parameter RMs . . . . . . . 85

6.5 Local Analysis of the Singular Set . . . . . . . . . . . . . 89

6.6 Examples . . . . . . . . . . . . . . . . . 92

6.7 Global Analysis of the Singular Set . . . . . . . . . . . . . 96

6.8 Escape from a Singular Configuration . . . . . . . . . . . . 99

Lecture 7 Variational Problems Associated with Kinematic $\begin{array}{ll}\text { Chains by } R \text {. Brockett } & 103\end{array}$

7.1 Variational Theories . . . . . . . . . . . . . . . . 103

7.2 Kinematic Chains as Maps of $T^{n}$ into a Lie Group . . . . . . 106

7.3 Kinematic Performance ... . . . . . . . . . . . . 107

Lecture 8 Computational Differential Algebra by B. Mishra 111

8.1 General Introduction . . . . . . . . . . . . . . . . 111

8.2 Differential Algebra and Some Open Problems . . . . . . . 114

8.2.1 Membership Problem . . . . . . . . . . . . 115

8.2.2 H-bases of Differential Ideals . . . . . . . . . . 117

8.2.3 Characteristic Sets . . . . . . . . . . . . . . 120

8.2.4 Formal Solutions of Differential Equations . . . . . . . 123

8.3 Applications . . . . . . . . . . . . . . 126 
8.3.1 Robotics. . . . . . . . . . . . . . . . . . 127

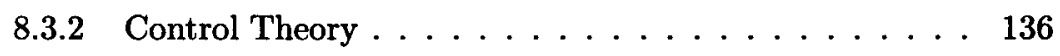

8.3 .3 Simulation .................. 141

8.4 Conclusion . . . . . . . . . . . . . . . . 142

Index 